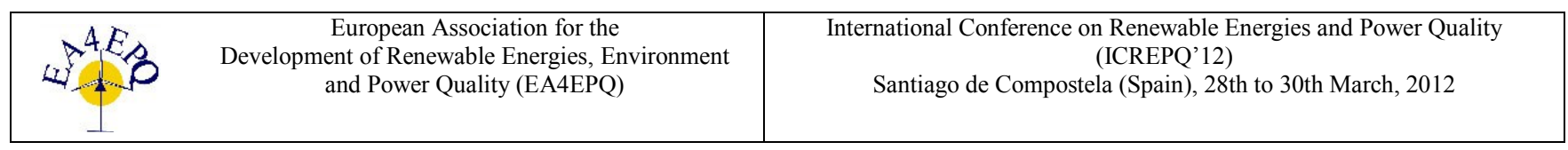

\title{
Determination of Controllers Constraints for Frequency Stability in Islanded Microgrid
}

\author{
M. Kohansal, G. B. Gharehpetian, M. Abedi and M. J. Sanjari \\ Electrical Engineering Department, Amirkabir University of Technology, Tehran. Iran \\ Phone/Fax number: +0098-21-64543504, \\ E-mail: mh.kohansal@aut.ac.ir,grptian@aut.ac.ir, abedi@aut.ac.ir,m_j_sanjari@aut.ac.ir
}

\begin{abstract}
With large scale integration of micro-generation into low voltage grids, stability becomes an important issue for a Microgrid (MG). The unique nature of the MG requires that it becomes stable in both grid-connected and islanded modes. In grid-connected mode, the main grid guarantees the stability of MG but in islanded mode, the stability is related to all elements of the system and their control units. In this paper, the changes in droop coefficient influencing the frequency stability of the MG are investigated in islanded MG. The simulation results determine the new constraint for controllers in MG.
\end{abstract}

\section{Key words}

MG, Frequency stability, Parallel inverters, VSI, Conventional droop method

\section{Introduction}

Driven by economical, technical, and environmental reasons, the energy sector is moving into an era where large portions of increases in electrical energy demand will be met through widespread installation of distributed resources, or what is known as distributed generation (DG) [1]. The use of DG increases the service reliability and reduces the need for future generation expansion or grid reinforcement. Moreover, it extends up the possibility of making the DG responsible for local power quality, voltage regulation, power factor correction, etc., in a way that is not possible with conventional centralized generators [2]. Unlike large generators, which are almost exclusively $50 / 60-\mathrm{Hz}$ synchronous machines, DG units include variable frequency (variable speed) sources (such as wind energy sources), high-frequency (high-speed) sources (such as microturbines), and direct energy conversion sources producing dc voltages or currents (such as fuel cells and photovoltaic sources). The majority of distributed resources are interfaced with the utility grid/loads via dc-ac inverter systems [3], [4]. There are several operating regimes possible for DG. Among them is the MG [5], [6], in which a cluster of DG units serviced by a distribution system is formed to maintain the reliability of critical loads, mainly when the utility supply is not available. However, a reliable and robust operation of a $\mathrm{MG}$ focuses on an efficient control scheme of $\mathrm{MG}$ generators.

The basic control objective in a MG is to achieve accurate power sharing while maintaining close regulation of the MG voltage magnitude and frequency. Centralized control of a $\mathrm{MG}$, based on a communication infrastructure, is investigated in [7]-[9]. However, in MGs, in remote areas with long connection distance between inverters, it is impractical and costly to distribute the dynamic sharing signals, which are characterized by their high bandwidth. Further, reliability issues of the centralized control approach might counteract the positive reliability boosts gained by implemented DG in MGs.

To overcome these limitations, decentralized controllers are reported. Droop controllers, which emulate the droop characteristic of synchronous generators, are proposed as power sharing controllers of MG generators [10]-[14]. A static droop compensator is utilized for power sharing in [10] and [11]. An enhanced droop control featuring a transient droop performance is proposed in [12]. To improve the active and reactive power decoupling performance, improved droop controllers with virtual output impedance are reported [12], [13]. To account for nonlinear loads, harmonic based droop controllers are investigated [15], [16]. In fact, the power sharing controller dictates the low-frequency dynamics of the inverter due to the time-scale separation between the power, voltage, and current dynamics. However, existing droop controllers are synthesized in the sense of the smallsignal model of the power transfer mechanisms; this can yield acceptable results for small load variation. In a typical MG system, the concept of "base-load" might not be applied; accordingly, large load variations are expected. In the sense of the MG dynamics, it can be shown that as the demanded power of each inverter changes, the low-frequency modes of the power sharing dynamics drift to new locations yielding different dynamic performance.

In particular, at higher power demands, the damping active/reactive powers required to stabilize the frequency/voltage are limited. In this case, the dominant modes of the power sharing dynamics move toward unstable region, making the system more oscillatory, and eventually, instability can be yielded. The low damping feature of the oscillatory power modes yields low 
frequency oscillations in the fundamental voltage and frequency oscillations will be imposed on the injected currents, which might excite unstable dynamics. In addition, the low damping of the power controller modes generates dynamic coupling among the active and reactive power components; yielding poor sharing and might force large transient startup and circulating currents.

In this paper, a general model of an islanded $\mathrm{MG}$ is presented. The presented model includes inverter, network load dynamics. All the sub-modules are individually modeled and constraints on frequency and active power are obtained.

\section{Modelling of MG elements}

In this section modeling of different elements that are commonly used in a MG are presented. These elements are divided in three groups:

\section{A. Voltage Source Inverter (VSI) Modelling}

Most of MG systems are made of a cluster of inverter based DG units empowered by microsources, such as fuel cells, microturbines, dc storage, etc. A dc/ac VSI is commonly used as an interfacing module. Fig. 1 shows a block diagram of a MG-connected VSI. A three-leg VSI with an $L C$ filter with a coupling inductor form the power circuit, whereas three control loops form the control structure. Specifically, a droop controller is used to generate the magnitude and frequency of the fundamental output voltage of the inverter according to the active and reactive power. A voltage controller is used to synthesize the reference filter-inductor current vector; and a current controller is adopted to generate the command voltage vector to be synthesized by a pulse-width-modulation (PWM) module. In this paper, the resistance of inductor is considered. In Park's $d-q$ frame rotating synchronously with the inverter output voltage angular speed $\omega 0$, the current and voltage dynamics can be reasonably represented by the following equations:

$$
\begin{aligned}
& \frac{d i_{d}}{d t}=\frac{-R f}{L f} i_{d}+\omega o i_{q}+\frac{1}{L f}\left(u_{d}^{*}-v_{o d}\right) \\
& \frac{d i_{q}}{d t}=\frac{-R f}{L f} i_{q}-\omega o i_{d}+\frac{1}{L f}\left(u_{q}^{*}-v_{o q}\right) \\
& \frac{d v_{o d}}{d t}=\omega o v_{o q}+\frac{1}{C f}\left(i_{d}-i_{o d}\right) \\
& \frac{d v_{o q}}{d t}=-\omega o v_{o d}+\frac{1}{C f}\left(i_{q}-i_{o q}\right) \\
& \frac{d i_{o d}}{d t}=\frac{-R c}{L c} i_{o d}+\omega o i_{o q}+\frac{1}{L c}\left(v_{o d}-v_{b d}\right) \\
& \frac{d i_{o q}}{d t}=\frac{-R c}{L c} i_{o q}-\omega o i_{o d}+\frac{1}{L c}\left(v_{o q}-v_{b q}\right)
\end{aligned}
$$

where $u_{d}^{*}, u_{q}^{*}, i_{d}$, and $i_{q}$ are the $d$ - and $q$-axis inverter's voltages and currents; $v_{\mathrm{o} d}, v_{\mathrm{o} q}, i_{\mathrm{o} d}$, and $i_{\mathrm{o} q}$ are the $d$ - and $q$-axis output voltages and currents; $v_{b d}$ and $v_{b q}$ are the $d$ and $q$-axis bus voltages, $R_{f}, L_{f}$, and $C_{f}$ are the per-phase resistance, inductance, and capacitance of the $L C$ filter, respectively; and $R_{c}$ and $L_{c}$ are the per-phase resistance and inductance of the coupling inductor, respectively.

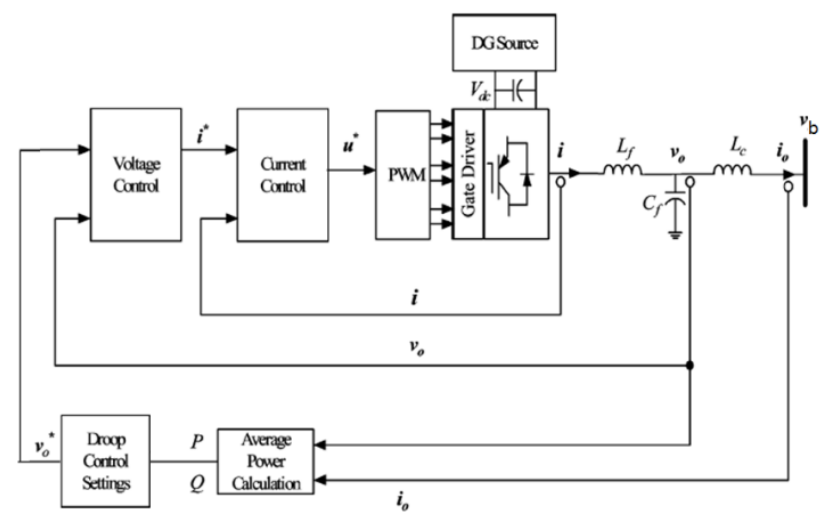

Fig. 1. Power circuit and control structure of MG-connected VSI

In this paper, both voltage and current controllers are PIcontrollers as described in [11]. These controllers have insignificant effect on VSIs stability while droop controller can highly affect stability. Consequently, the equations of droop controller are discussed here.

Using the two-axis theory, the injected instantaneous active and reactive power components, $p$ and $q$, are given by:

$p=v_{o d} i_{o d}+v_{o q} i_{o q}$
$q=v_{o d} i_{o q}-v_{o q} i_{o d}$

To allow sufficient time-scale separation between the power and current control loops and to achieve high power quality, the average active and reactive powers corresponding to the fundamental components are subjected to control action, and they are obtained by means of a low-pass filter as:

$P=\frac{\omega_{c}}{s+\omega_{c}} p$

$Q=\frac{\omega_{c}}{s+\omega_{c}} q$

where $\omega_{c}$ is the filter cut-off frequency.

To realize a power sharing function, the conventional droop characteristics are usually used in paralleled inverter systems to introduce the following droops in the fundamental voltage frequency and magnitude of the output voltage:

$\omega_{o}=\omega^{*}-m_{p} P$

$v_{o d}^{*}=V^{*}-n_{q} Q$

where $\omega^{*}$ and $V^{*}$ are the nominal frequency and voltage set points, respectively, and $m_{p}$ and $n_{q}$ are the static droop gains. The set points in (11) and (12) act as a virtual communication agent for different inverters for autonomous operation.

\section{B. Network Modelling}

On a common reference frame, the state equations of line current of $i$-th line connected between nodes $\mathrm{j}$ and $\mathrm{k}$ are:

$\frac{d i_{\text {line }_{\text {id }}}}{d t}=\frac{-R_{\text {line }_{i}}}{L_{\text {line }_{i}}} i_{\text {line }_{\text {id }}}+$ wo $_{\text {line }_{\text {iq }}}+\frac{1}{L_{\text {line }_{i}}}\left(v_{j d}-v_{k d}\right)$
$\frac{d i_{\text {line }_{\text {iq }}}}{d t}=\frac{-R_{\text {line }_{i}}}{L_{\text {line }_{i}}} i_{\text {line }_{i q}}-\omega o i_{\text {line }_{i d}}+\frac{1}{L_{\text {line }_{i}}}\left(v_{j q}-v_{k q}\right)$ 


\section{B. Load Modelling}

Although, many types of load can exist in MGs, a general RL load is considered in this paper. The state equations of the RL load connected at $i$-th node are:

$\frac{d i_{\text {load }_{\text {id }}}}{d t}=\frac{-R_{\text {load }_{i}}}{L_{\text {load }_{i}}} i_{\text {load }_{\text {id }}}+$ wo $_{\text {load }_{\text {iq }}}+\frac{1}{L_{\text {load }_{i}}}\left(v_{\text {id }}\right)$
$\frac{d i_{\text {load }_{\text {iq }}}}{d t}=\frac{-R_{\text {load }_{i}}}{L_{\text {load }_{i}}} i_{\text {load }_{\text {iq }}}-$ oo $_{\text {load }_{\text {id }}}+\frac{1}{L_{\text {load }_{i}}}\left(v_{\text {iq }}\right)$

\section{Simulation Results}

A complete model of the test system was obtained through the procedure outlined in section 2 . The test system is shown in Fig. 2 and the parameters values are gathered in table I. In all of the simulations, the $n_{q}$ is kept equal to $1.5 \mathrm{e}-4$ and the effect of varying the $m_{p}$ is investigated.

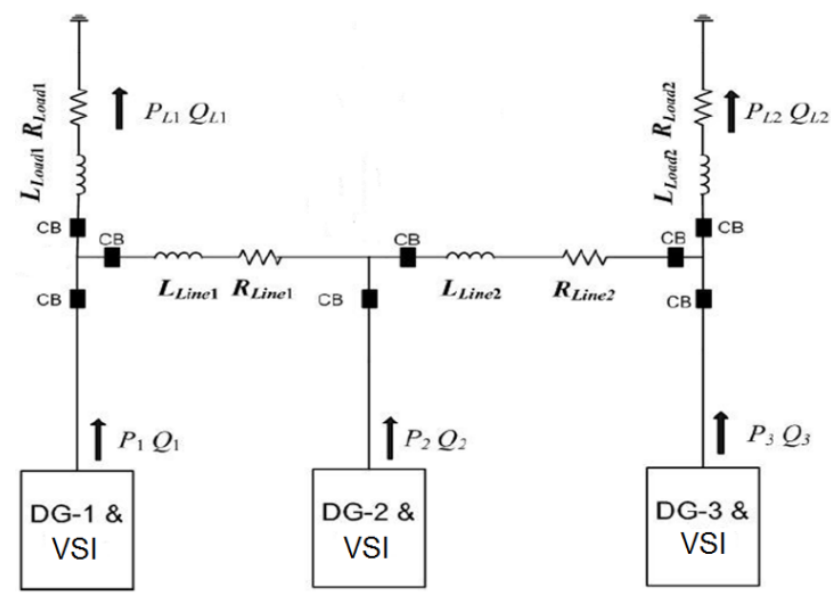

Fig. 2. Test system schematic

Table I. Values of test system parameters

\begin{tabular}{|c|c|c|c|}
\hline Parameter & Value & Parameter & Value \\
\hline$L_{f}$ & $1.35 \mathrm{mH}$ & $\omega_{0}{ }^{*}$ & $314 \mathrm{rad} / \mathrm{sec}$ \\
\hline$R_{f}$ & $0.1 \Omega$ & $V^{*}$ & $380 \mathrm{~V}$ \\
\hline$C_{f}$ & $50 \mu \mathrm{F}$ & $R_{\text {line } 1}$ & $0.23 \Omega$ \\
\hline$L_{c}$ & $0.35 \mathrm{mH}$ & $L_{\text {line } 1}$ & $3.2 \mathrm{mH}$ \\
\hline$R_{c}$ & $0.03 \Omega$ & $R_{\text {line } 2}$ & $0.35 \Omega$ \\
\hline$\omega_{c}$ & 31.4 & $L_{\text {line } 2}$ & $3.14 \mathrm{mh}$ \\
\hline$K_{p v}$ & 0.05 & $R_{\text {load } 1}$ & $25 \Omega$ \\
\hline$K_{i v}$ & 390 & $L_{\text {load } 1}$ & $1.5 \mathrm{mH}$ \\
\hline$K_{p c}$ & 10.5 & $R_{\text {load } 2}$ & $20 \Omega$ \\
\hline$K_{i c}$ & $16 \mathrm{e} 3$ & $L_{\text {load } 2}$ & $1.1 \mathrm{mH}$ \\
\hline
\end{tabular}

Fig. 2 shows the complete eigenvalues places of the system for the $m_{p}=1 \mathrm{e}-4$. This diagram is obtained by linearzing the state equations which are expressed in section 2 . As it can been seen, all of the eigenvalues are placed in the left half and consequently, the system is stable. In this case, the active output power and frequency response of the VSIs are shown in Fig.3 and Fig.4, respectively. As a result of droop controller, the active power shares equally between inverters.

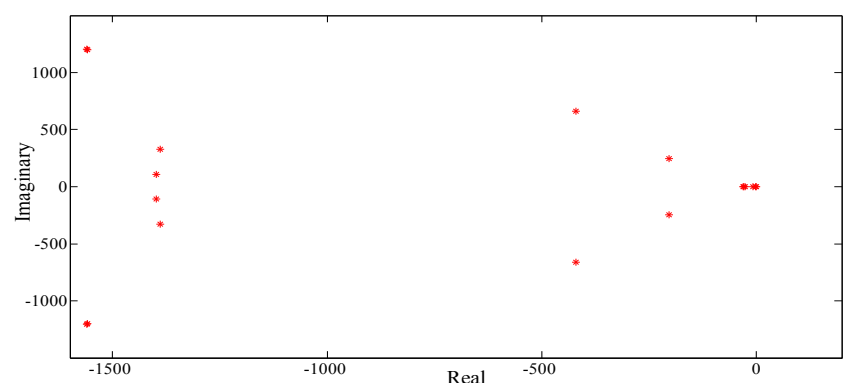

Fig. 2. Complete eigenvalues of system for the $m p=1 e-4$.

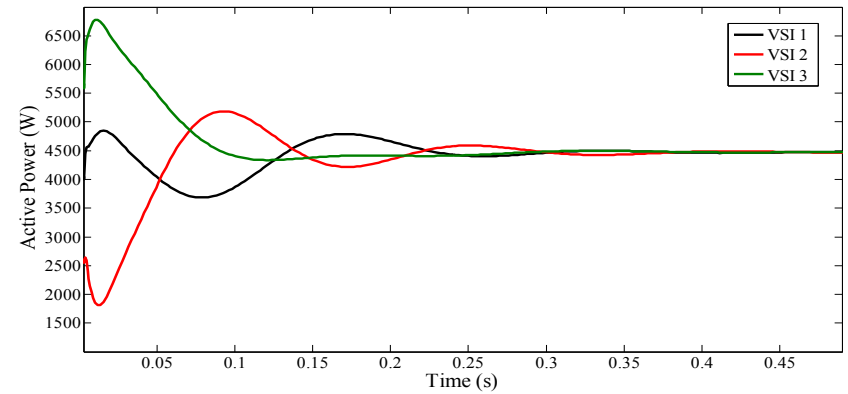

Fig. 3. Active output power response of VSIs to a disturbance when $m p=1 e-4$

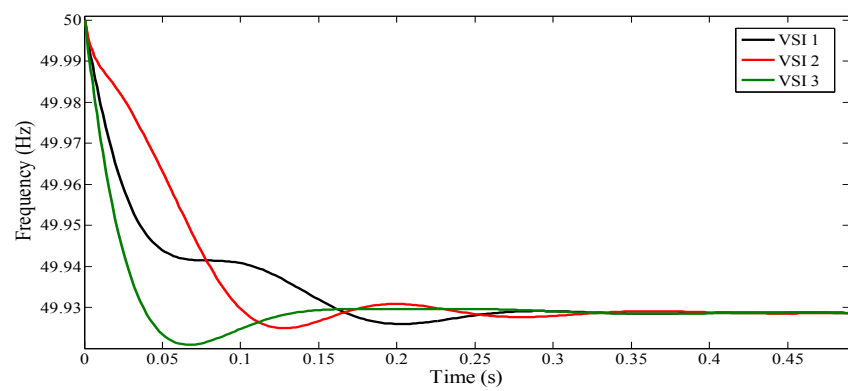

Fig. 4. Frequency response of VSIs to a disturbance when $\mathrm{mp}=1 \mathrm{e}-4$

Fig.5 shows the trajectory of two-pairs of complexconjugate dominant low frequency eigenvalues as a function of the real power droop gain.

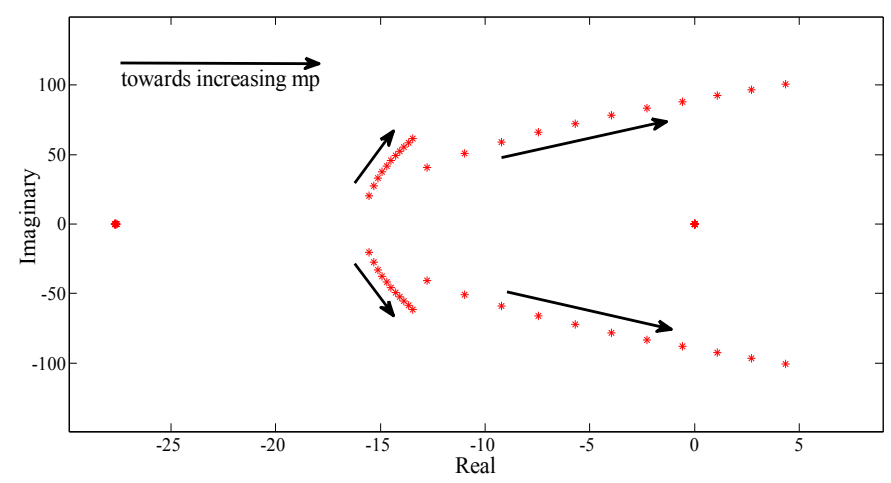

Fig. 5. Movement of two-pairs of complex-conjugate dominant low frequency eigenvalues

The movement of real part of the dominant low frequency eigenvalues as a function of the real power droop gain is shown in Fig.6. 


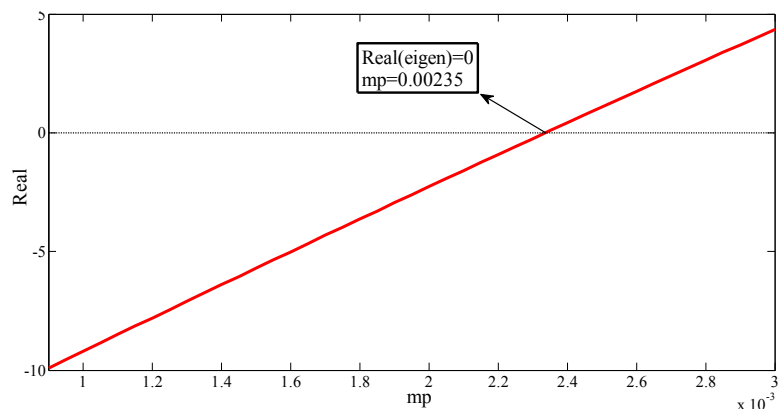

Fig. 6. Movement of real part of dominant low frequency eigenvalues

As shown in Fig.6, the stability margin of the system decreases when $\mathrm{m}_{\mathrm{p}}$ in increased. For example, when $m_{p}$ is set equal to 0.003 , the system is expected to be instable. To validate this phenomenon, consider Fig.7 and Fig.8, in which the response of unstable system $\left(m_{p}=0.003\right)$ are shown.

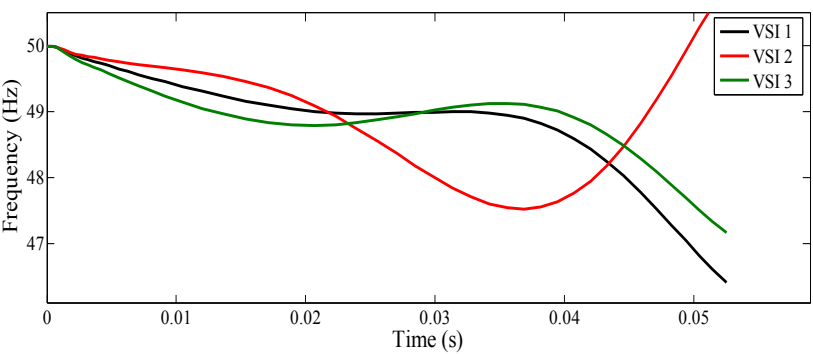

Fig. 7. Frequency response of VSIs to a disturbance when $\mathrm{m}_{\mathrm{p}}=0.003$

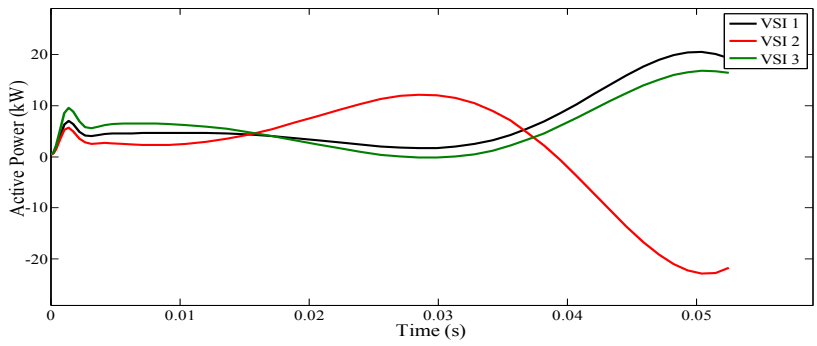

Fig. 8. Active output power response of VSIs to a disturbance when $\mathrm{m}_{\mathrm{p}}=0.003$

Considering Fig.6, the constraint $m_{p}<0.00235$ should be added to every controller design or this constraint should be added to controllers output as a controller upper limiter.

\section{Conclusion}

In this paper, a general model of an islanded $\mathrm{MG}$ is presented. This model includes inverters, network and load dynamics. All the sub-modules are individually modeled and are then combined into a common reference frame to obtain the complete model of the MG. The eigenvalues of the model have been analyzed to find their sensitivity to changes in the gain of real power droop. With the help of this analysis, the frequency stability constraint has been achieved for every controller that controls the real power droop gain.

\section{References}

[1] R. Lasseter and P. Piagi, "Providing premium power through distributed resources", Proc. 33rd Hawaii International Conference on System Science, January 2000.

[2] F. Blaabjerg, Z. Chen, and S. B. Kjaer, "Power electronics as efficient interface in dispersed power generation systems," IEEE Trans. Power Electron., vol. 19, no. 5, pp. 1184-1194, Sep. 2004.

[3] F. Blaabjerg, R. Teodorescu, M. Liserre, and A. V. Timbus, "Overview of control and grid synchronization for distributed power generation systems," IEEE Trans. Ind. Electron., vol. 53, no. 5, pp. 1398-1409, Oct. 2006.

[4] M. Dai, M. Marwali, J. Jung, and A. Keyhani, "Power flow control of a single distributed generation unit," IEEE Trans. Power Electron., vol. 23, no. 1, pp. 343-352, Jan. 2008.

[5] R. H. Lasseter, "Microgrids," in Proc. Power Eng. Soc. Winter Meeting, Jan. 2002, vol. 1, pp. 305-308.

[6] N. Hatziargyriou, H. Asano, R. Iravani, and C. Marnay, "Microgrids," IEEE Power Energy Mag., vol. 5, no. 4, pp. 78-94, Jul./Aug. 2007.

[7] J. A. P. Lopes, C. L. Moreira, and A. G. Madureira, "Defining control strategies for MGs islanded operation," IEEE Trans. Power Syst., vol. 21, no. 2, pp. 916-924, May 2006.

[8] M. Kohansal, M. J. Sanjari, G. B. Gharehpetian "A novel approach to frequency control in an islanded microgrid by load shedding scheduling", in Proc. ICREPQ. Conf., 2011.

[9] F. Pilo, G. Pisano, G.G. Soma, "Neural Implementation of MG Central Controllers", 5th IEEE International Conference on Industrial Informatics, 2007.

[10] M. C. Chandorkar and D. M. Divan, "Control of parallel connected inverters in standalone AC supply system," IEEE Trans. Ind. Appl., vol. 29, no. 1, pp. 136-143, Jan./Feb. 1993.

[11] F. Katiraei and M. R. Iravani, "Power management strategies for a microgird with multiple distributed generation units," IEEE Trans. Power Syst., vol. 21, no. 4, pp. 1821-1831, Nov. 2006.

[12] J. Guerrero, L. de Vicuna, J. Matas, M. Castilla, and J. Miret, "A wireless controller to enhance dynamic performance of parallel inverters in distributed generation system," IEEE Trans. Power Electron., vol. 19, no. 5, pp. 1205-1213, Sep. 2004.

[13] S. J. Chiang, C. Y. Yen, and K. T. Chang, "A multimodule parallelable series-connected PWM voltage regulator," IEEE Trans. Ind. Electron., vol. 48, no. 3, pp. 506-516, Jun. 2001.

[14] M. Kohansal, J. S. Moghani, B.Abdi, G. B. Gharehpetian, "A Control Method to Enhance Dynamic Performance of Parallel Inverters in Islanded Microgrid," to be appeared., IEEE ACEMP. Conf., 2011.

[15] U. Borup, F. Blaabjerg, and P. Enjeti, "Sharing of nonlinear load in parallel connected three-phase converters," IEEE Trans. Ind. Appl., vol. 37, no. 6, pp. 1817-1823, Nov./Dec. 2001.

[16] T. Lin and P. Cheng, "Design of a new cooperative harmonic filtering strategy for distributed generation interface converters in an islanding network," IEEE Trans. Power Electron., vol. 22, no. 5, pp. 1919-1927, Sep. 2007. 